\title{
Novos táxons em Hemilophini (Coleoptera, Cerambycidae, Lamiinae)
}

\author{
Ubirajara R. Martins ${ }^{1,3}$ \& Maria Helena M. Galileo ${ }^{2,3}$
}

\begin{abstract}
${ }^{1}$ Museu de Zoologia, Universidade de São Paulo. Caixa Postal 42494, 04218-970 São Paulo, São Paulo, Brasil.
2 Museu de Ciências Naturais, Fundação Zoobotânica do Rio Grande do Sul. Caixa Postal 1188, 90001-970 Porto Alegre, Rio Grande do Sul, Brasil.

${ }^{3}$ Pesquisador do CNPq.
\end{abstract}

\begin{abstract}
New taxa in Hemilophini (Coleoptera, Cerambycidae, Lamiinae). New taxa described: Icimauna pallidipennis sp. nov. from Costa Rica (Puntarenas); from Brazil - Apagomerina gigas sp. nov. (Santa Catarina) and A. lampyroides sp. nov. (Pará, Mato Grosso); from Ecuador - Tyrinthia aurantia sp. nov. (Pichincha); Unaporanga gen. nov., type-species, U. lanceolata sp. nov. from Ecuador (Los Ríos) and U. cincta sp. nov. from Panama (Darien). KEYWORDS. Apagomerina; Icimauna; Tyrinthia; Unaporanga.
\end{abstract}

RESUMO. Novos táxons descritos: Icimauna pallidipennis sp. nov. da Costa Rica (Puntarenas); do Brasil - Apagomerina gigas sp. nov. (Santa Catarina) e A. Iampyroides sp. nov. (Pará, Mato Grosso); do Equador - Tyrinthia aurantia sp. nov. (Pichincha); Unaporanga gen. nov., espécie-tipo, U. Ianceolata sp. nov. do Equador (Los Ríos) e U. cincta sp. nov. do Panamá (Darien).

PALAVRAS-CHAVE. Apagomerina; Icimauna; Tyrinthia; Unaporanga.

Material recebido para estudo do National Museum of Natural History, Washington, enviado por Steven Lingafelter, do American Coleoptera Museum, San Antonio, por James Wappes e do Carnegie Museum of Natural History, Pittsburgh, remetido por Robert Davidson, facultou-nos a descrição de seis espécies novas e um gênero inédito.

As novas espécies pertencem: uma ao gênero Icimauna proposto por Martins \& GaliLEo (1991) que contém seis espécies descritas desde a Costa Rica até o Brasil meridional (Rio Grande do Sul), Paraguai e Argentina; duas de Apagomerina Gilmour, 1962, gênero que agrupa 12 espécies e que foram discriminadas em chave por Martins \& Galileo (1996: 24).

Tyrinthia Bates, 1866 foi estudado por Martins \& Galileo (1991) que dividiram o gênero com base na fronte dos machos desarmada ou com projeções tuberculiformes. A espécie que ora descrevemos está baseada numa fêmea, portanto, não podemos saber se a fronte dos machos possui ou não tubérculos.

Unaporanga gen. nov. é estabelecido para duas espécies e assemelha-se aos gêneros Iareonycha Martins \& Galileo, 1997 e Lapazina Lane, 1973.

As siglas utilizadas no texto correspondem a American Coleoptera Museum, San Antonio (ACMS); Carnegie Museum of Natural History, Pittsburgh (CMNH); National Museum of Natural History, Washington (USNM) e Museu de Zoologia, Universidade de São Paulo, São Paulo (MZSP). As dimensões são fornecidas em milímetros.

\section{Icimauna pallidipennis sp. nov.}

Fig. 1

Etimologia. Latim, pallidus = pálido, pennis = élitro; alusivo ao colorido amarelado dos élitros.

Fêmea. Cabeça amarelada menos partes látero-superiores da fronte e regiões atrás dos olhos, pretas. Olhos divididos. Antenas pretas com anel basal amarelado nos antenômeros V$\mathrm{X}$; atingem o meio dos élitros. Escapo, antenômeros III e IV do mesmo comprimento. Flagelômeros com longos pêlos no lado interno e pêlos curtos no lado externo.

Protórax castanho-escuro com borda anterior amarelada. Pronoto densamente pontuado. Escutelo preto.

Élitros amarelados com o oitavo apical preto-acastanhado. Pontuação presente em toda a superfície. Pêlos abundantes, amarelados, principalmente na metade apical.

Procoxas amareladas; coxas e trocanteres amarelados. Fêmures, tíbias e tarsos, pretos. Face ventral do corpo, preta.

Dimensões. Comprimento total, 6,8-6,9 comprimento do protórax, 1,0-1,2; maior largura do protórax, 1,0-1,1 comprimento dos élitros, 4,9-5,0; largura umeral, 1,3-1,4.

Material-tipo. Holótipo fêmea, Costa Rica, Puntarenas: Coronado, I. 1926, T. Assmann leg., ex-Col. Nevermann, 1940, (USNM, NH 2033782). Parátipos: mesmos dados do holótipo, fêmea (USNM), fêmea (MZSP).

Discussão. Icimauna pallidipennis sp. nov. assemelha-se a 
I. angaba Martins \& Galileo, 1991 pelo colorido geral amarelado. Difere pelo vértice amarelado, pelos olhos divididos, pelo escapo, antenômero III e IV subiguais em comprimento, pelo antenômero $\mathrm{V}$ com anel basal amarelado, pelo pronoto acastanhado com orla anterior amarelada, pela extremidade elitral escurecida, pela pubescência dos élitros muito mais esparsa e curta e pelos fêmures pretos.

Em I. angaba, o vértice é percorrido no centro por faixa preta, os olhos são inteiros, antenômero III é mais longo que o escapo e o IV é mais curto que os dois anteriores, o antenômero V é amarelado com o anel apical escuro, o pronoto possui faixa longitudinal preta no meio, os élitros são inteiramente amarelados e providos de pubescência densa e longa e a base dos fêmures é avermelhada.

\section{Apagomerina gigas sp. nov.}

Fig. 2

Etimologia. Latim, gigas = gigante; alusivo às dimensões.

Fêmea. Cabeça preta. Genas revestidas por pubescência branca. Faixa de pubescência branca que se inicia entre os tubérculos anteníferos e bifurca-se em direção ao occipício. Antenas pretas, flagelômeros com anel basal avermelhado. Antenômero III, o mais longo, com franja esparsa no lado interno.

Protórax preto. Pronoto com duas faixas oblíquas de pubescência branca, da base ao ápice; essas faixas são em continuação àquelas do occipício; região central do terço posterior com tubérculo brilhante; pontuação esparsa. Lados do protórax com gibosidade arredondada, situada atrás do meio. Partes laterais do protórax pontuadas.

Élitros acastanhados, margens da base ao quinto apical, com pubescência branca que é em continuação das faixas pronotais. Friso sutural revestido por pubescência branca. Élitros finamente pontuados. Extremidades elitrais arredondadas.

Coxas e trocanteres avermelhados. Profêmures pretos com base avermelhada. Meso- e metafêmures pretos. Tíbias e tarsos pretos.

Mesosterno avermelhado para os lados. Metasterno preto. Urosternitos I, II e V pretos; III e IV revestidos por densa pubescência esbranquiçada.

Dimensões. Holótipo fêmea, comprimento total, 19,9; comprimento do protórax, 3,4; maior largura do protórax, 4,9; comprimento dos élitros, 15,0; largura umeral, 5,6.

Material-tipo. Holótipo fêmea, BRASIL, Santa Catarina: Joinvile, II.1927, ex-Col. Tippmann (USNM, NH 2033782).

Discussão. Apagomerina gigas sp. nov. distingue-se de todas as espécies do gênero por apresentar os urosternitos III e IV revestidos por densa pubescência branca e pelas grandes dimensões.

\section{Apagomerina lampyroides sp. nov.}

Fig. 3

Etimologia. Alusivo ao abdômen semelhante aos órgãos luminescentes dos lampirídeos.
Fêmea. Cabeça preta; região occipital coberta por pubescência esbranquiçada disposta em V. Fronte com pubescência esbranquiçada e genas com pubescência branca, densa. Escapo avermelhado no lado interno e preto no lado externo. Antenômero III acastanhado com franja de pêlos esparsos no lado interno; comprimento igual ao dobro daquele do escapo. Antenômeros IV e V alaranjados; do VI ao X com o ápice progressivamente mais escuro até inteiramente no XI. Ponta das antenas aproxima-se das extremidades elitrais.

Protórax alaranjado, com os lados amplamente cobertos por pubescência branca; essa pubescência praticamente ocupa toda a borda anterior do pronoto. Gibosidades laterais apenas indicadas. Pontuação pronotal fina e densa

Élitros alaranjados, escurecidos no dorso, do meio ao ápice; este escurecimento alarga-se gradualmente para o ápice. Frisos sutural e marginal revestidos por pubescência branco-amarelada.

Pro- e mesofêmures alaranjados. Metafêmures pretoalaranjados. Tíbias e tarsos castanhos. Esternos torácicos alaranjados e escurecidos em algumas regiões. Urosternitos I e V acastanhados; pubescência amarelada reveste os lados do urosternito II e, inteiramente, os urosternitos III e IV.

Variabilidade. No parátipo, os élitros são totalmente escurecidos no dorso, com os frisos marginal e sutural mais avermelhados.

Dimensões. Comprimento total, 11,9-12,4; comprimento do protórax, 1,9-2,2; maior largura do protórax, 2,8-2,9; comprimento dos élitros, 8,5-9,4; largura umeral, 3,4-3,6.

Material-tipo. Holótipo fêmea, Brasil, Pará: IX, Acc. $\mathrm{n}^{\circ}$ 2966 (CMNH). Parátipo fêmea, Brasil, Mato Grosso: Chapada dos Guimarães, XI, Acc. n 2966 (MZSP).

Discussão. Apagomerina lampyroides sp. nov. difere de $A$. gigas sp. nov. pelas menores dimensões; pelo escapo avermelhado com lado externo preto; pelos antenômeros IV-VI alaranjados; pela pubescência esbranquiçada que avança para o centro do pronoto junto à orla anterior e para os lados do protórax; pelo disco pronotal sem tubérculo; pela gibosidade lateral do protórax mais discreta e pela faixa de pubescência esbranquiçada dos élitros que, na base, não está soldada com a margem.

Em A. gigas as dimensões são maiores; o escapo é preto; os antenômeros III e IV são pretos; a pubescência do pronoto está restrita às faixas laterais; o disco do pronoto tem pequeno tubérculo; a gibosidade lateral do protórax é manifesta e a faixa de pubescência esbranquiçada da margem dos élitros é soldada com ela desde a base.

\section{Tyrinthia aurantia sp. nov. \\ Fig. 4}

Etimologia. Latim, aurantia = alaranjado; alusivo ao colorido geral.

Fêmea. Cabeça alaranjada com pubescência amarelada, visível conforme a incidência da luz. Lobos oculares superiores tão distantes entre si quanto a largura de um lobo. Escapo 


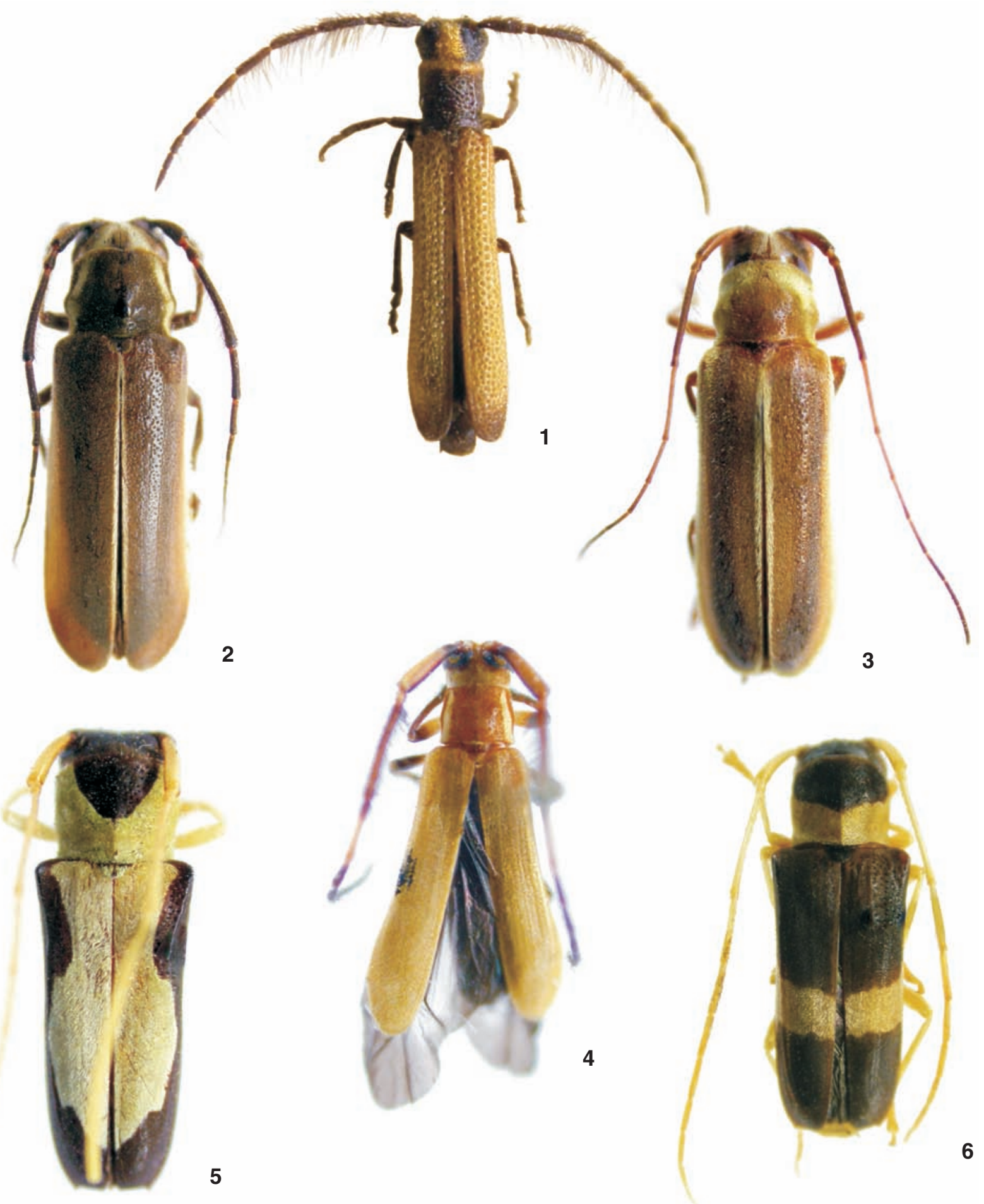

Figuras 1-6. Habitus: (1) Icimauna pallidipennis sp. nov., parátipo fêmea, comprimento 6,8 mm; (2) Apagomerina gigas sp. nov., holótipo fêmea, comprimento 19,9 mm; (3) Apagomerina lampyroides sp. nov., holótipo fêmea, comprimento 12,4 mm; (4) Tyrinthia aurantia sp. nov., holótipo fêmea, comprimento $7,8 \mathrm{~mm}$; (5) Unaporanga lanceolata sp. nov., holótipo fêmea, comprimento 11,0 mm; (6) Unaporanga cincta sp. nov., holótipo fêmea, comprimento 10,2 mm. 
alaranjado e preto num estreito anel basal; comprimento pouco menor que o do antenômero III. Antenômero III alaranjado coberto por densos pêlos pretos, os do lado interno, mais longos que o dobro da largura do artículo. Antenômero IV, amarelado com anel basal preto. Antenômero V preto com anel basal amarelado. Demais antenômeros pretos.

Protórax alaranjado. Lados do pronoto com faixa estreita de pubescência esbranquiçada, da base ao ápice. Disco pronotal pontuado, menos na região centro-posterior, lisa. Escutelo alaranjado.

Élitros amarelados.

Profêmures alaranjados com o ápice preto; mesofêmures alaranjados com o terço apical preto. Metafêmures pretos com estreita área basal alaranjada. Protíbias pretas na face dorsal e alaranjadas na ventral. Meso- e metatíbias quase inteiramente pretas. Tarsos pretos.

Prosterno e esternos do mesotórax, alaranjados. Metepisternos e centro do metasterno, pretos; lados do metasterno alaranjados. Urosternitos pretos.

Dimensões. Holótipo fêmea, comprimento total, 7,8; comprimento do protórax, 1,2; maior largura do protórax, 1,4; comprimento dos élitros, 5,7; largura umeral, 2,0.

Material-tipo. Holótipo fêmea, EQUADor, Pichincha: $45 \mathrm{~km}$ S de Santo Domingo (Rio Palenque Res. Sta., 220 m), 7.XII.1993, J. B. Heppner leg. (ACMS).

Discussão. Pelo colorido inteiramente amarelado dos élitros, Tyrinthia aurantia sp. nov. assemelha-se a T. picticornis Martins \& Galileo, 1991, originalmente descrita do Panamá e a T. dioneae Martins \& Galileo, 2004 procedente da Colômbia. Distingue-se pela cabeça, escapo e antenômero III alaranjados e profêmures alaranjados com o ápice preto. Em T. picticornis a cabeça tem áreas pretas, os antenômeros são pretos com anel basal alaranjado e os profêmures são alaranjados. Em T. dioneae as antenas também são aneladas e a franja de pêlos do antenômero III é esparsa.

\section{Unaporanga gen. nov.}

Etimologia. Tupi, una = besouro; poranga = bonito; alusivo ao padrão de colorido das espécies.

Espécie-tipo, Unaporanga lanceolata sp. nov.

Cabeça da mesma largura que o protórax. Fronte (fêmea) quadrangular, plana. Lobos oculares superiores tão distantes entre si quanto a largura de um lobo. Mandíbulas com ápice entalhado. Antenas com onze artículos; ultrapassam o ápice elitral. Escapo subcilíndrico, tão longo quanto dois terços do comprimento do antenômero III; sem cicatriz. Antenômero III ligeiramente sinuoso; com franja interna de pêlos moderadamente densos. Antenômero IV mais longo do que o V com pêlos semelhantes ao do III; V-X com comprimento decrescente e pêlos também semelhantes ao do III.

Protórax mais longo do que largo e ligeiramente mais estreito posteriormente do que anteriormente. Pronoto sem tubérculo.
Élitros com comprimento igual a pouco mais do que o dobro da largura umeral. Úmeros projetados e agudos quando vistos de perfil. Lados com duas carenas subcontíguas, do úmero até o quarto apical; a carena externa ultrapassa posteriormente a umeral. Extremidades elitrais transversalmente truncadas com espículo externo.

Processo prosternal muito estreito entre as procoxas. Processo mesosternal pouco mais estreito entre as mesocoxas; entalhado no ápice. Metasterno acentuadamente convexo. Metepisternos largos, com os lados estreitados para trás.

Fêmures sublineares; o ápice dos posteriores atinge o meio do urosternito III. Garras tarsais com dente interno mais longo do que o externo. Urosternitos III-V com pubescência branca, densa (tipo lampiróide).

Discussão. Pelas carenas elitrais contíguas, Unaporanga gen. nov. assemelha-se a Iareonycha Martins \& Galileo, 1997 e Lapazina Lane, 1973.

Difere de Iareonycha pelas antenas das fêmeas mais longas que o corpo; pelos élitros com pouco mais do dobro da largura umeral, pelo dente interno das garras tarsais mais longo que o interno; pelo protórax apenas mais largo anteriormente do que na base e sem projeções laterais. Em Iareonycha as antenas atingem o terço apical dos élitros; os élitros são mais longos que o quádruplo da largura umeral; o dente interno das garras tarsais é mais curto que o externo; o protórax é tão largo na base como anteriormente e os lados com gibosidade discreta.

Em Lapazina, o dente interno das garras tarsais também é mais longo que o externo; mas Unaporanga gen. nov. difere pela presença de espículo no lado externo do ápice dos élitros, pelo protórax sem intumescimento mediano, pelas mandíbulas com o ápice bífido e pelas manchas de pubescência branca nos urosternitos. Em Lapazina, o ápice dos élitros é arredondado e desarmado, o protórax é intumescido no meio dos lados, o ápice das mandíbulas não é bífido e os urosternitos não têm pubescência branca e densa.

\section{Unaporanga lanceolata sp. nov.}

\section{Fig. 5}

Fêmea. Cabeça preta. Antenas amareladas. Protórax com pubescência densa, amarelada e uma área triangular, grande, glabra, do meio para diante. Partes laterais do protórax cobertas por pubescência amarelada; área no limite com o prosterno preta. Élitros cobertos por pubescência branco-amarelada numa grande área dorsal, da base até o sexto apical, com bordas irregulares que em conjunto lembram uma ponta de lança. Epipleuras pretas. Prosterno e mesosterno pretos. Processo mesosternal preto-avermelhado. Pernas avermelhadas. Pubescência branca reveste os esternos do mesotórax. Urosternito I preto com estreita área revestida por pubescência amarelada na borda posterior. Urosternitos II-IV cobertos por pubescência amarelada. Urosternito $\mathrm{V}$, preto.

Dimensões. Holótipo fêmea, comprimento total, 11,0; comprimento do protórax, 2,5; largura anterior do protórax, 
3,0; largura da base do protórax, 2,8; comprimento do élitro, 7,8; largura umeral, 3,7.

Material-tipo. Holótipo fêmea, EqUADOR, Los Rios: Quevedo (40 km N, Rio Palenque Biol. Station), 12.III.1979, J.J. Anderson leg. (USNM, NH 2033782).

\section{Unaporanga cincta sp. nov.}

Fig. 6

Fêmea. Cabeça preta. Antenas amareladas. Pronoto com a metade anterior preta e a metade posterior coberta por pubescência branco-amarelada; o limite entre estas colorações, em forma de "V" com ramos bem abertos. Partes laterais do protórax revestidos por pubescência esbranquiçada, menos no limite com o prosterno.

Élitros pretos indistintamente avermelhados ao redor do escutelo; faixa subtransversal de pubescência amarelada, logo depois do meio.

Mesosterno preto. Processo mesosternal avermelhado. Demais esternos mesotorácicos e os metatorácicos, avermelhados cobertos por pubescência esbranquiçada. Metepisternos com mancha longitudinal preta

Pernas amareladas. Urosternito I (exceto pequena área centro-posterior) e $\mathrm{V}$ pretos. Urosternito II preto nos lados e branco no meio. Urosternito III branco e o IV branco nos lados e preto em estreita região central.

Dimensões. Holótipo fêmea, comprimento total, 10,2; comprimento do protórax, 2,4; largura anterior do protórax, 2,5; largura do estreitamento basal do protórax, 2,4; comprimento dos élitros, 7,2; largura umeral, 3,5.

Material-tipo. Holótipo fêmea, Panamá, Darien: Cana Ancon Station $\left(7^{\circ} 45,323^{\prime} \mathrm{N}, 77^{\circ} 41,069^{\prime} \mathrm{W}, 500 \mathrm{~m}\right), 3-9 . V I .1996$, S. Lingafelter leg. (USNM, NH 2033782).

Discussão. Unaporanga cincta sp. nov. separa-se de $U$. lanceolata pelo padrão de colorido inteiramente diferente.

\section{AGRADECIMENTOS}

Aos pesquisadores James Wappes (ACMS), Robert Davidson (CMNH) e Steven Lingafelter (USNM) que nos enviaram material para estudo. A Eleandro Moysés (Museu de Ciências Naturais, Fundação Zoobotânica do Rio Grande do Sul, Porto Alegre) pelas fotografias e montagem da estampa.

\section{REFERÊNCIAS BIBLIOGRÁFICAS}

Martins, U.R. \& M.H.M. Galileo. 1991. O gênero Tyrinthia Bates, 1866 e gêneros afins (Coleoptera, Cerambycidae, Lamiinae, Hemilophini). Revista Brasileira de Entomologia 35 (4): 813824.

Martins, U.R. \& M.H.M. Galileo. 1996. Transferência de gêneros de Aerenicini para Hemilophini, novos táxons e chave para as espécies de Apagomerina Gilmour, 1962 (Coleoptera, Cerambycidae, Lamiinae). Revista Brasileira de Entomologia 40 (1): 21-24.

Recebido em 28.VI.2007; aceito em 27.XI.2007. 